\title{
ON THE ASSESSMENT OF EXPOSURE TO AIRBORNE ULTRAFINE PARTICLES IN URBAN ENVIRONMENTS
}

\author{
João Fernando Pereira Gomes1,2, João Carlos Moura Bordado1, Paula Cristina Silva \\ Albuquerque3
}

1IBB - Instituto de Biotecnologia e Bioengenharia/Instituto Superior Técnico-Universidade Técnica de Lisboa, Lisboa, Portugal

2ISEL - Instituto Superior de Engenharia de Lisboa, Área Departamental de Engenharia Química, Lisboa, Portugal 3ESTESL - Escola Superior de Tecnologia da Saúde de Lisboa-Instituto Politécnico de Lisboa, Lisboa, Portugal

The aim of this study was to contribute to the assessment of exposure levels of ultrafine particles in the urban environment of Lisbon, Portugal, due to automobile traffic, by monitoring lung deposited alveolar surface area (resulting from exposure to ultrafine particles) in a major avenue leading to the town center during late spring, as well as in indoor buildings facing it. Data revealed differentiated patterns for week days and weekends, consistent with PM2.5 and PM10 patterns currently monitored by air quality stations in Lisbon. The observed ultrafine particulate levels may be directly correlated with fluxes in automobile traffic. During a typical week, amounts of ultrafine particles per alveolar deposited surface area varied between 35 and $89.2 \mu \mathrm{m}_{2} / \mathrm{cm}_{3}$, which are comparable with levels reported for other towns in Germany and the United States. The measured values allowed for determination of the number of ultrafine particles per cubic centimeter, which are comparable to levels reported for Madrid and Brisbane. In what concerns outdoor/indoor levels, we observed higher levels (32 to 63\%) outdoors, which is somewhat lower than levels observed in houses in Ontario.

The authors thank Rita Santos and Prof. Teresa Vieira, from Coimbra University, for their help in ultrafine particulate characterization.

Also they thank ACT-Autoridade para as Condições do Trabalho for partially fund this study under project 035APJ/09. Address correspondence to João Fernando Pereira Gomes, Instituto de Biotecnologia e Bioengenharia/Instituto Superior TécnicoUniversidade Técnica de Lisboa, Av. Rovisco Pais, 1049-001 Lisboa, Portugal. E-mail: jgomes@deq.isel.ipl.pt 